Article

\title{
Women's Safety and Public Spaces: Lessons from the Sabarmati Riverfront, India
}

\author{
Darshini Mahadevia ${ }^{1}$ and Saumya Lathia ${ }^{2, *}$ \\ ${ }^{1}$ School of Arts and Sciences, Ahmedabad University, 380009 Gujarat, India; E-Mail: darshini.mahadevia@ahduni.edu.in \\ 2 Sol Price School of Public Policy, University of Southern California, Los Angeles, CA 90089, US; E-Mail: slathia@usc.edu \\ * Corresponding author
}

Submitted: 1 March 2019 | Accepted: 3 May 2019 | Published: 30 June 2019

\begin{abstract}
The Sustainable Development Goals 5 and 11, as well as the New Urban Agenda, emphasize gender equity and safe, resilient, and inclusive cities. The 'safe cities' idea for women includes their equal right to the city and public places within it, which includes their right to be mobile in the city at any time of the day, as well as their right to loiter in public spaces without any threats of harassment or sexual violence. These issues have gained importance in urban planning and design in contemporary India. This article is an assessment of how safe Ahmedabad city's largest public space, the Sabarmati Riverfront, is for women. Ahmedabad, a city in western India, has long carried an image of a safe city for women. The Sabarmati Riverfront is over $22 \mathrm{~km}$ in length, $11 \mathrm{~km}$ on both sides of the river. This assessment is made through mapping of space use disaggregated by sex and age at four different time points throughout the day and of 100 women's accounts of the experience of harassment on using the space. The article concludes with specific recommendations on proposed activities and space design along the riverfront to make these spaces safe for women throughout the day.
\end{abstract}

\section{Keywords}

gender; harassment; India; public space; riverfront; safety; women

\section{Issue}

This article is part of the issue "Public Space in the New Urban Agenda: Research into Implementation", edited by Michael W. Mehaffy (KTH Royal Institute of Technology, Sweden), Tigran Haas (KTH Royal Institute of Technology, Sweden), and Peter Elmlund (Axel and Margaret Ax:son Johnson Foundation, Sweden).

(C) 2019 by the authors; licensee Cogitatio (Lisbon, Portugal). This article is licensed under a Creative Commons Attribution 4.0 International License (CC BY).

\section{Introduction}

The Sustainable Development Goals (SDGs) 5 and 11, as well as the New Urban Agenda, emphasize gender equitable and safe, resilient and inclusive cities. This implies women can enjoy city life in its fullest dimension as much as men. In other words, women have as much of a right to the city as men. Although the 'right to the city' is mediated by existing social inequities of class, religion, race, ethnicity, and caste in the Indian context (Kabeer, 1994), above all these equities is a layer of gender inequality. Gender refers to "culturally-mediated expectations and roles associated with masculinity and femininity" (Lips, 2015 , p. 2). Gender roles are shaped by economic, cultural, and social norms and play a significant part in con- structing unequal urban realities. Simply put, "women and men experience cities in different ways" (Beall, 1996, p. 10). Violence against Women (VAW), a global movement, captures how violence or the threat of violence against women fuels this differential experience. Another important aspect is the ability to 'loiter' in the city and seek pleasure without demonstrating a 'respectable purpose' (Phadke, Ranade, \& Khan, 2009). While the forms of violence or its threat vary depending on social and political situations, these threats of violence, violence, and social stigma against purposeless loitering in the city are experienced by all women. Therefore, in this article, we use the term women and not gender.

The agenda of VAW addresses the fulfillment of two SDGs: gender equity (SDG 5) and safe, inclusive cities, 
and resilient cities (SDG 11). Women across cultures experience violence in their day-to-day lives. The United Nation's (UN) 'Declaration on the Elimination of Violence against Women' states (UN Human Rights, 1993): "Violence against women is a manifestation of historically unequal power relations between men and women." It further states: "Violence against women constitutes a violation of the rights and fundamental freedoms of women and impairs or nullifies their enjoyment of those rights and freedoms." This UN Declaration defines violence against women as "any act of gender-based violence that results in, or is likely to result in, physical, sexual, or psychological harm or suffering to women, including threats of such acts, coercion or arbitrary deprivation of liberty, whether occurring in public or in private life" (UN Human Rights, 1993). Hence, both actual violence and the threat of violence are construed as violence.

Although violence against women is legally prohibited in many countries, the veil of superstition and cultural and age-old religious practices continue to violate women's rights. Women's constant exposure to various forms of violence in their daily lives reinforces gender inequality and curtails their mobility in cities and urban spaces. This 'daily' and 'normal' nature of violence or the fear of it often restricts or alters their interaction with the city. It also undermines their 'right to public space' and, consequently, their 'right to the city', understood as a state where every citizen has an equal right and access to the city and its public spaces (UNHABITAT, Department of Women and Child Development, Government of NCT of Delhi, Jagori, \& UN Women, 2010).

The women's right to a public place is embedded in the concept of 'safety'. What is women's safety? It is largely referred to in the societal narratives and policy discourses as a condition wherein they are free of sexual assault and harassment; while for men, the term safety refers to being free of all types of violence (Desai, Parmar, $\&$ Mahadevia, 2017). Although women also experience robberies and road accidents and hence are not safe, the preoccupied notion of associating women's bodies with their families' 'honor' makes their sexual safety of the utmost importance. Phadke (2007, p. 1512) argues:

The insistence on sexual safety actively contributes to not just reducing women's access to public space but also to compromise their safety when they do access public space, by focusing more on women's capacity to produce respectability rather than on their safety. The discourse of safety then does not keep women safe in public; it effectively bars them from it.

Literature on women's safety in India indicates that women are under the threat of different risks while accessing public spaces, even if they haven't experienced direct violence (Phadke, 2007, p. 1511): (i) potential physical assault, including risk of life or injury causing physical or psychological trauma; (ii) risk of 'reputation', resulting in loss of matrimonial opportunity or questioning of sexual virtue (iii) risk of being blamed for being 'in the wrong place' or 'at the wrong time' (especially in cases of physical or sexual assault), resulting in the improbability of finding justice; (iv) risk of no or minimal interaction with the city, leading to a loss of opportunity and experiences. In case of any harassment, society often engages in victim-blaming (Sur, 2014), perpetuates that a potential act of violence annihilates a woman's 'virtue', instead of her 'autonomy', and teaches young girls to 'protect their virtue at all costs.'

Therefore, women often hesitate to be in a public space without a 'legitimate' reason, as they are always looked upon as 'illegitimate' users of public spaces. Women feel the need to demonstrate their 'purpose' for being in public space and rarely tend to sit in a park by themselves, or stand at a street corner, or smoke, or simply watch the world go by like men do. Many activists, scholars, and feminists believe true women empowerment lies in enabling women to 'loiter' in the city as discussed above (Phadke et al., 2009). In the quest to create safe spaces for women, entry-barriers are installed which, in effect, in a hierarchized society such as India, tends to exclude the 'undesirables', read men from lowincome and caste or men from other social segments. Thus, women's activists in India also emphasize that the public spaces cannot be made safe for women at the cost of anyone else's ('undesirable' sections of the society like lower-class men) freedom. Public spaces should be truly 'public'; they must be accessible to everyone throughout the day. Translated into public space terms, this means that the right of every citizen-across class, caste, gender, religion, and sexual orientation must be protected. The city can only belong to the women, when it belongs to everyone (Phadke, 2007).

"How can we assert that women are at risk in public spaces while simultaneously rejecting representations that project women only as victims in need of protection, which will inevitably move towards restrictions, surveillance, and control?" (Phadke, 2005, p. 59). Across cultures, women's safety is usually considered to be the individual's responsibility rather than that of the state or society. Therefore, if women face violence in public spaces, they are either scolded for 'being out at the wrong time' or 'provoking the men' or are advised to protect themselves by carrying pepper sprays, small knives, heavy bags, key chains between their knuckles, wear heels or enrol in self-defence classes. Restricting women's mobility in the city cannot be a solution to women's safety; as women have as much right to loiter in the city as men (Phadke et al., 2009). This means that the issue of women's safety must be included in urban planning and design.

For us, women's safety in a public space, therefore, means both their safety from all forms of violence (including sexual harassment) and moving away from the patriarchal idea of honor; enabling women to freely engage with the city. It includes, first, creating safe public spaces, where women can move freely, at their will, at all times. This is important because 
"space which causes fear restricts movement and thus the community's use of space. Lack of movement and comfort is a form of social exclusion" (UNHabitat Women in Cities International, SIDA, Huairou Commission, \& CISCSA, 2008). It further includes:

Strategies, practices, and policies which aim to reduce gender-based violence (or VAW), including women's fear of crime and freedom from poverty. This includes safe access to water, the existence and security of communal toilet facilities in informal settlements, slum upgrades, gender-sensitive street and city design, safe car parks, shopping, and public transportation. (UNHabitat et al., 2008)

There are multiple approaches to women's safety in the city. The first one is focused on better surveillance in the city, largely through policing efforts of the community or security personnel. Closed Circuit Televisions (CCTV) cameras are often referred to as an important aspect of formal surveillance, while some consider it to be intrusive of personal space. Next is the legal approach to make women's harassment a cognizable crime meriting strict and swift legal action. The third one is changing socio-cultural norms through gender awareness training and education. The last one focuses on strategies for built-environment, including gender-aware and gender-sensitive (borrowing from Moser, 1993) urban planning and design. This approach focuses on (i) land-use strategies such as mixed land uses, so that there are no parts of the city that are deserted at any time of the day; (ii) public transport strategies such as the provision of frequent and well-connected public transport as well as a station and stops that are safe at all times of the day; and (iii) designing of public spaces that feel safe. Additionally, studies in the Indian context argue that the presence of people and other users like street vendors that act as 'eyes on the streets', make travel on the streets safe (Jagori, 2007, 2010; Parichiti, 2012; SAKHI, 2011; Vishwanath \& Mehrotra, 2007). In the next section, we turn to a discussion on the relationship between the built environment and women's safety.

\section{Women's Safety and Built Environment}

Built environment refers to the human-made structures that provide space for human activities, interactions, and community life. It ranges from buildings and neighborhoods to community gardens and green spaces, from water supply and drainage to the transportation system and so on. Modern built environment discussions also range from design \& aesthetics, construction \& management, and public health \& safety, to its economy and policies.

Men and women experience spaces differently. Traditionally, men have occupied and therefore dominated public spaces. The traditional division of labor and gender roles often confined women to their homes. Rapid urbanization and modernization enabled women to engage with the public realm for various reasons. Although gender is not the only or primary axis of discrimination in public spaces, it is a significant one.

Women feel insecure in public spaces due to multiple factors like poor design and infrastructure, society's behavioral pattern, shortcomings of the education system (towards gender relations, sexuality), and economic disparity. Apart from the built environment elementslike streetlights, state of sidewalks, maintenance of public spaces, dark/abandoned buildings or areas, areas of visual or hearing isolation, etc. - the type of users and footfall largely affects women's perception of safety. Dhar (2013) states women feel safer with 'eyes on the street' (presence of people, vendors, drivers, etc.), a concept popularized by Jane Jacobs (1992) in the context of American neighborhood planning. Women in Delhi identified 'disrespect for women' as a major concern while using public transport:

Girls and women who travel on RTVs (road transport vehicles/buses) face constant harassment from drivers, conductors, and their associates, who make vulgar comments, play loud suggestive songs, or crowd against women and push or rub against them. (Jagori, 2007, p. 36)

Similarly, most city streets are predominantly designed for automobiles and often comprise on the safety of pedestrians. To mitigate this, the cities build pedestrian crossings, foot over-bridges, or underpasses. These are usually poorly-designed, highly inconvenient to use, and perceived as unsafe for the fear of being mugged and sexually assaulted.

Based on numerous studies (ActionAid International, 2013; UNHABITAT et al., 2010; Jagori, 2007, 2010; SAKHI, 2011; Women in Cities International, 2010a, 2010b) conducted in both the developed and the developing world, the built environment factors that affect women's perception of safety are:

\subsection{Proper Lighting}

Dark street corners, entry/exit points, car-parks, and poorly lit spaces cause discomfort to women during early mornings and late evenings, increasing the fear of violence. Women across the world have reported being willing to take longer or different routes to avoid such spots and stretches (UNHABITAT et al., 2010). Safety audits in Delhi highlighted that women felt unsafe in almost all carparks, which are generally poorly-lit and are less visually accessible from the entry/exit points. This scares women from getting into their cars after dark (Vishwanath \& Mehrotra, 2007, p. 1546). Conversely, women tend to use well-lit spaces or routes.

\subsection{Quality of Public Spaces}

Poorly-maintained spaces like broken sidewalks, unfixed potholes, open defecation, streetlights blocked by over- 
grown trees, etc. generate fear of violence, accidents, and health issues in women. Conversely, well-maintained and hygienic spaces make women, especially older or disabled women, feel safe. Wide, walkable sidewalks free of urinating men, cleaner spaces, shaded pathways, etc. increase convenience and safety in a public space.

\subsection{Extent of Oversight in Public Spaces}

Women prefer being in familiar areas, or in spaces where they can call for help or run away if they face violence, or spaces that are active and eventful. Hence, it bothers them to be in spaces that make them invisible. "Together for women's safety" (UNHABITAT et al., 2010; Women in Cities International, 2010a) articulates the three major concerns of women in public spaces very well: to see and to be seen, to hear and to be heard, and to get away and get help. Different user groups like 'middle-aged people', 'older adults', 'women', 'families', 'familiar vendors $\&$ shopkeepers', etc. make women feel more secure and safe (Jagori, 2011, p. 44).

\subsection{Empty/Dilapidated Building or Plots}

Women feel uncomfortable walking on streets with large empty walls or empty plots due to fear of not getting help in case of assault. Empty or dilapidated buildings are often favorable spots for men engaging in illicit activities, amplifying the fear of violence. In safety audits, the participants claimed to experience a greater fear of assault or rape in deserted spaces (Jagori, 2010, p. 17).

\subsection{Extent of Familiar People/Shops/Vendors}

The presence of people, familiar shopkeepers and vendors enhance informal surveillance in public spaces, making women feel safer. Plus, vendors and shops also ensure activity generation round-the-clock, ensuring more informal surveillance throughout the day (Vishwanath \& Mehrotra, 2007, p. 1547).

\subsection{Places with Visible and accessible Police Booths, Patrolling, CCTV Coverage, etc.}

As discussed previously, deserted and visually inaccessible spaces make women feel unsafe. Hence, spaces that are well-patrolled, have formal or informal surveillance, or are close to emergency stations and police stations make women feel they can be heard and helped, and hence, safer (Jagori, 2011).

\subsection{Male Dominated Spaces}

Women find large groups of men intimidating and prefer avoiding those spaces, even if they are well-lit or well-maintained. Women feel safer around other women and men with their families. These unsafe spaces in the Indian context are cigarette shops, 'dhabas' (roadside tea and food stalls on highways), taxi stands, certain street corners, liquor shops, or certain deserted parks (Vishwanath \& Mehrotra, 2007, p. 1547).

\subsection{Status of Public Toilets}

The inadequate public facilities make the lives of women from poorer/slum/resettlement areas acutely vulnerable. Public toilets in poor neighborhoods are often in a filthy and vandalized state, and hence unusable. Women have reported public toilets in those areas to be extremely unsafe as the male attendants often harass the women or frequently peek or break into the toilets. Men's and women's public toilets located close to each other increase instances of verbal and visual violence through the open roofs (Jagori, 2007; Parichiti, 2012), while the absence of toilets forces women to defecate in the open. To protect their modesty, women defecate in the open at night, falling victim to increased incidents of sexual harassment. Women report frequent encounters of flashing, staring, or stalking in these fields and public toilets (Vishwanath \& Mehrotra, 2008).

\section{Methodology}

This article is an assessment of the largest public open space, a riverfront, from the perspective of women and the extent to which it is perceived as safe by women. Our inquiry questions were: (i) to what extent women use this public space, (ii) are there any preferred spots they use, (iii) are single women coming to this space, (iv) whether women users have experienced harassment while using this space, and ( $v$ ) what interventions do women suggest to make this public space safer and more useable.

This study is in Ahmedabad City, with a population of 6.5 million as per 2011. The city is segmented by class, caste, and religion (Mahadevia, Desai, \& Vyas, 2014). The Sabarmati River passes through the heart of the city. Eastern Ahmedabad, home to the Walled City of Ahmedabad is industrial and largely houses low-income populations. Western Ahmedabad is more globalized, with high-end real estate development and gated communities inhabited by the wealthy. Ahmedabad's transformation since the early 2000s has involved the spatial restructuring of the city through numerous beautification and infrastructure projects that aim at improving the city's image, attracting investment and boosting the quality of life for the city's middle/upper-middle class (Desai, 2014). The Sabarmati Riverfront Development is one such project.

The Sabarmati Riverfront, the city's award-winning project, is aimed at rejuvenating the Sabarmati River to create the city's largest public space. It is an artificially created riverfront which was carried out by reclaiming the riverbed. The project has created a riverfront area stretching $11.5 \mathrm{~km}$ along both sides of the riverbank. By channeling the river to a constant width of $263 \mathrm{~m}$, 202.79 hectares of riverbed land were reclaimed. This 
project was supposed to create the city's first public space large enough to host multiple public activities. Various stretches of riverfront were still under construction at the time of this research.

Mixed methods have been used for the study. In the preliminary stage, activities were mapped along the entire $11.5 \mathrm{~km}$ stretch on both sides of the river between the months of January-March (2016). Through this mapping, four pockets, two on each side of the river, which had a footfall of people, were identified for detailed study. Thereafter, the elements (positive and negative) affecting the perception of safety, as identified in the literature review, were listed and mapped along with the activity mapping in the four selected pockets. This was followed by an in-depth study of the gendered usage of space for three different time slots of the day. Lastly, 100 female users ( 50 on each side of the river) were surveyed using a structured questionnaire as well as unstructured discussion wherein questions were asked about their social background, their experiences of harassment on the riverbank, their opinion about elements that made a space safe or unsafe, and what actions could be taken to improve the safety of women on the riverbank. We did not ask them what could be done to increase the use of this large public space by women as only during the survey did we find a high gender imbalance in the same. The sample size for the survey was equally distributed across all the pockets as well as all times of the day.

\section{Preliminary Assessment}

Riverfront rejuvenation planning started in the late 1960s, but its final plan was approved in mid-2000. After massive evictions and the displacement of 11,000 poor urban households living on the riverbanks (Mahadevia, 2014), riverfront construction began in 2009. The 11.5 $\mathrm{km}$ of reclaimed land along riverbed was distributed for open spaces, development sites, public utility, and roads. The Lower Promenade is designed at the low-tide line and submerges into the river during floods. The Upper Promenade is designed at the high-tide line of the river to prevent frequent flooding in the adjoining neighborhoods. Large roads on each side of the Riverfront were designed to increase accessibility to the river and reduce traffic congestion. This decision was criticized for underutilizing city's prime land for roads instead of city amenities and open space. Ironically, public transport and paratransit services are prohibited on these roads, limiting access to the Riverfront to those who own private vehicles. Furthermore, sidewalks on both sides of these roads are discontinuous and vary in size. The high volume of fastmoving traffic makes it unsafe to walk on the road or cross the same.

Parks on both sides of the river only have a few functional access points. People usually gather around the access points of the parks, leaving the linear ends of the park usually deserted. For maximum visibility into the parks from the streets, most parks (except the Flower
Park on the west) have fences instead of compound walls. People prefer clustering in and around Ghats (stepped passage to the river) and other access points like stairways and ramps on the Lower Promenade. The Lower Promenade, in most stretches, especially towards the access points, is insufficiently lit and lacks bright signage. Stretches like A, B, I, parts of E and F, have largely damaged lighting, failing to attract larger footfalls and families (refer to Figure 1). The Upper Promenade on both sides of the river is comparatively well lit, better maintained, and more functional.

Once the proposed spaces are completely constructed, it is expected to draw large crowds. But at the time of our survey, large stretches, especially on the east were deserted (refer Figure 2). Many toilets were not functional and lacked bright signage and lighting. The western side of the Riverfront offered a wider range of spaces and amenities like MyByk Stations, Boating Stations, food kiosks, Events Ground, Sports Facility, Flower Park, Plazas, etc. attracting more people than the eastern side (refer Figure 2). The presence of MyByk stations on the western side enables more cyclists to bike on the Lower Promenade. Young men and couples use the vacant stretches of $C, D, E, G$ \& $H$ for recreation. Families are usually near more planned spaces like the parks, plazas, etc.

\section{Specific Pocket Assessment}

\subsection{Pocket 1: Usmanpura Park to Vallabh Sadan (between Stretch $C, D$ )}

Located on the western side of the river, Pocket 1 is one of the most popular spots on the Riverfront. The pocket is divided in two because of a bridge (called Gandhi Bridge) connecting the west of the river to the east. An important religious place, namely Vallabh Sadan, is in this pocket along the Upper Promenade and has a large open space towards the river making this spot favorable for hosting major events in the city like concerts, kite festivals, etc. Towards the north of this pocket is a park, called Usmanpura Park, which is frequented by the city's college-going youth due to its proximity to the city's large University Area.

The Lower Promenade in Pocket 1 is extensively used by people to jog and exercise from early morning to around 9 am. After that, the parking area in the Upper Promenade is more active than other parts of the pocket. It is largely used by youth from adjoining colleges for recreation (refer to Figure 3a). Despite the pocket being active, many women reported facing harassment as they feel the pocket becomes a male-dominated space, especially on the Lower Promenade after 9 am. A 21-year-old Hindu respondent said: "During early mornings, people deliberately come closer and pass uncharitable remarks on the Lower Promenade or in the parking area! Especially if one is spotted in a couple! This has happened to me many times." 


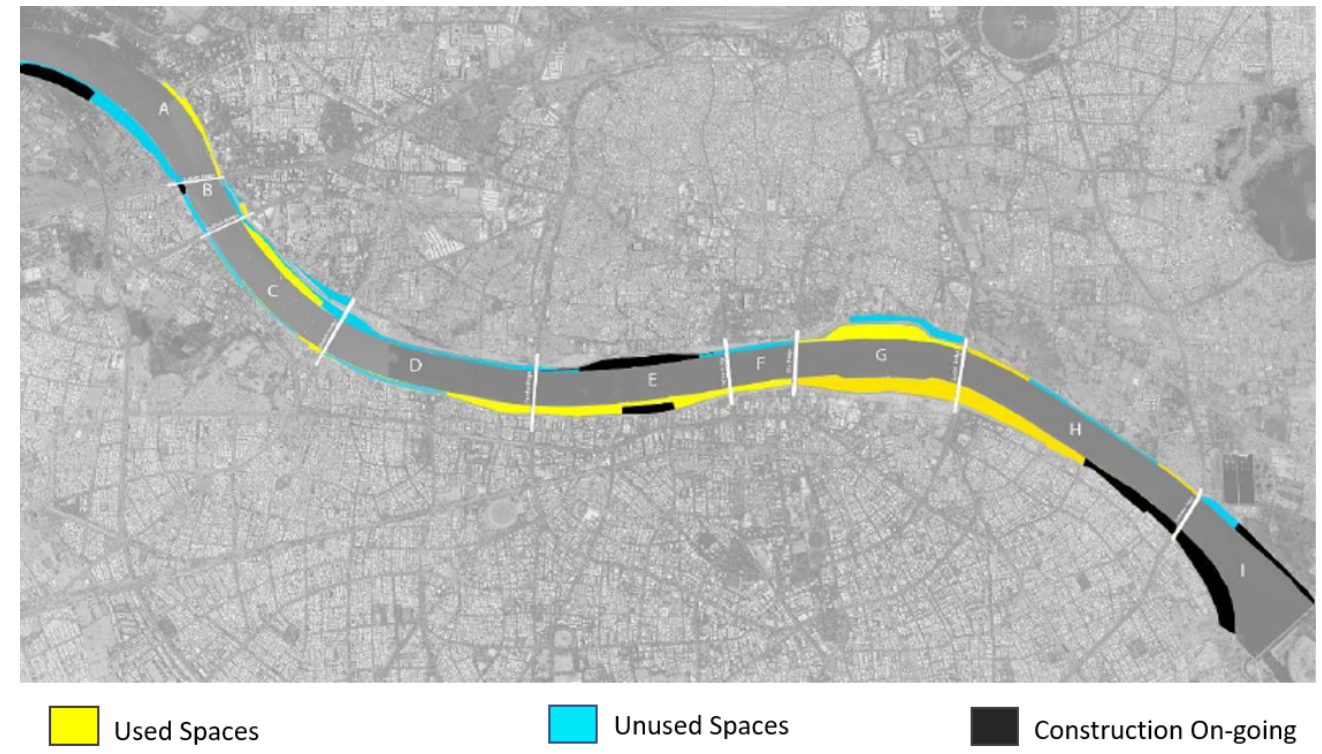

a. Used and Unused Spaces on the Riverfront

Original Image Source: Improving Women's Safety on Sabarmati Riverfront, Center for Urban Equity, $2017^{-}$

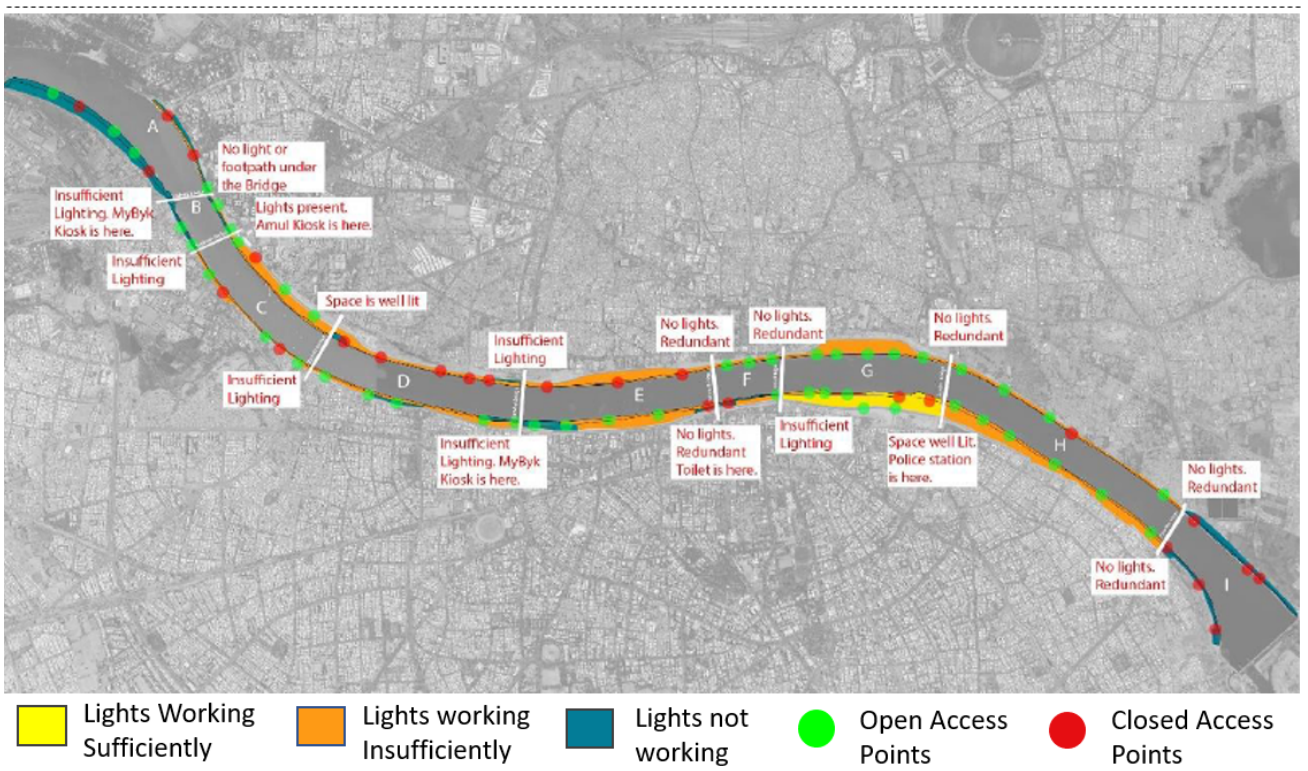

b. Status of Luminosity on the Riverfront

Original Image Source: Improving Women's Safety on Sabarmati Riverfront, Center for Urban Equity, $2017^{\circ}$

Figure 1. Status of infrastructure on the Riverfront.

Afternoons bring more people to the Pocket than the mornings, the predominant user group being the youth. The heat and weather conditions force most users to crowd in shaded spaces, such as the area under the bridge on the Lower Promenade. Except for that spot, most of the Lower Promenade is deserted. Young couples seeking privacy are found on the stairs between the Upper Promenade and Lower Promenade (refer to Figure $3 b$ ). The difference in elevation between both promenades in Pocket 1 is $12 \mathrm{~m}$. This massive height difference makes the Lower Promenade visually inaccessi- ble and more prone to sexual harassment, robbery, and other unwanted advances. Many women reported being harassed on the Lower Promenade due to lack of people around them. The design element of this pocket creates a perception of lack of safety.

In the evening, the boat station and the food kiosks on the Lower Promenade are a major attraction. The Lower Promenade is densely populated with families, older adults, and children, making the space much more vibrant than at other times of the day. The Upper Promenade, especially towards the northern stretch, is 


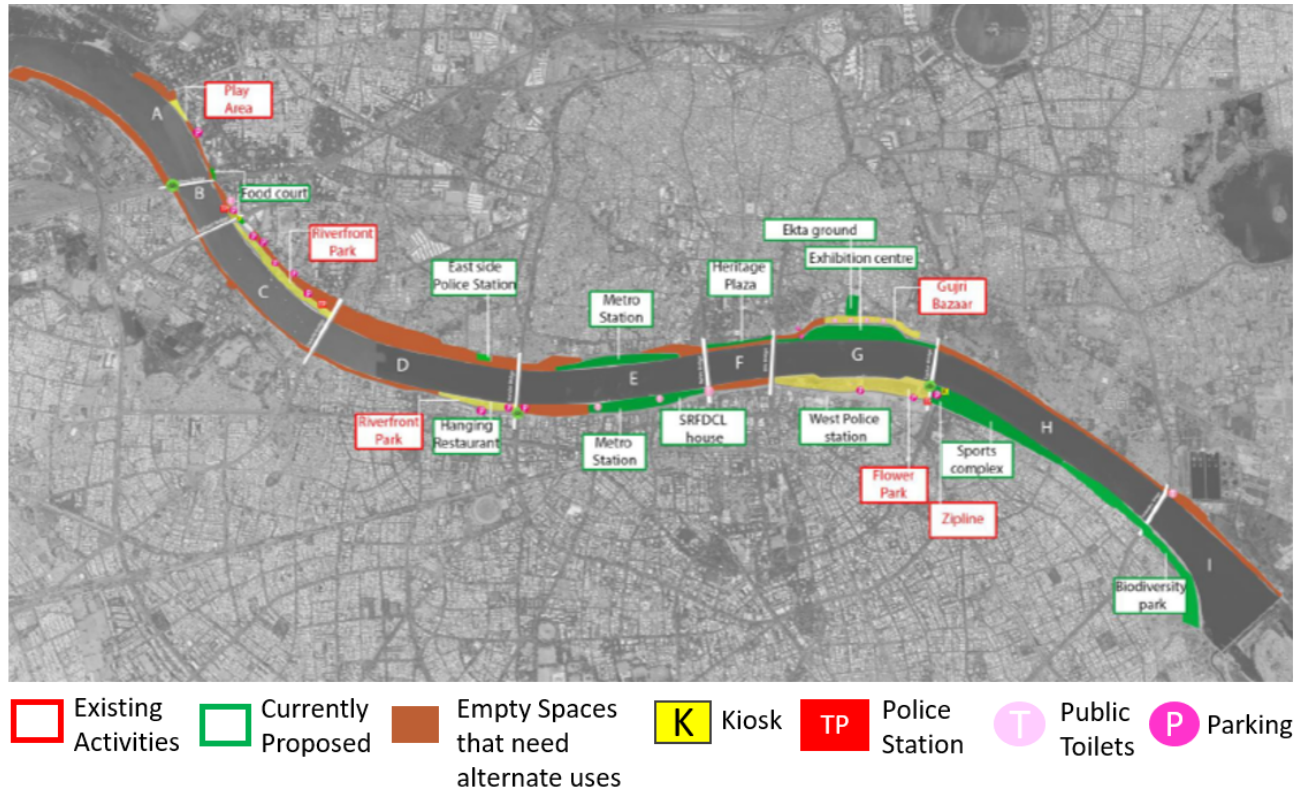

a. Existing \& Proposed Activities on the Riverfront

Original Image Source: Improving Women's Safety on Sabarmati Riverfront, Center for Urban Equity, 2017

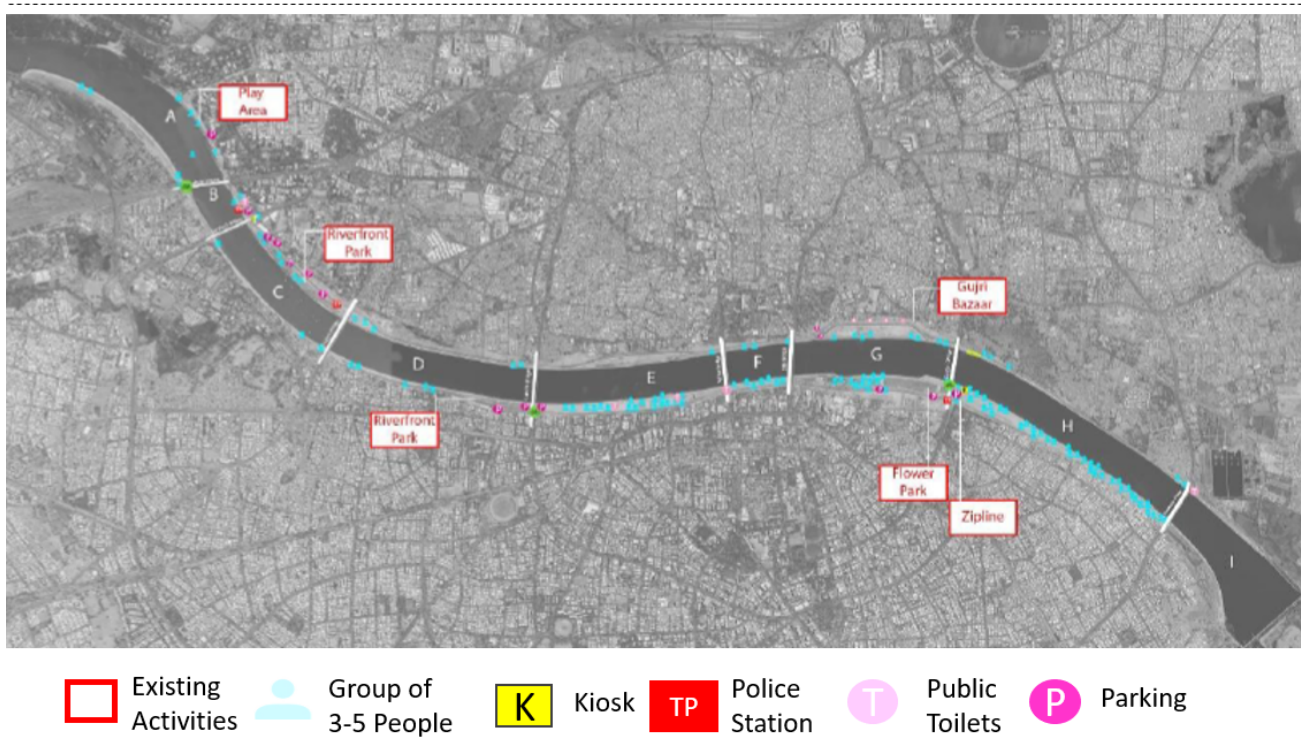

b. Footfall on the Riverfront

Original Image Source: Improving Women's Safety on Sabarmati Riverfront, Center for Urban Equity, 2017

Figure 2. Activity provision and footfall on the Riverfront.

poorly lit and mainly used for parking (refer to Figure 3c). Women reported feeling relatively safer in the evening due to the presence of more people, largely with families, on the Lower Promenade. Women feel safe here in the evening due to activities that bring in people.

Around $47 \%$ of the interviewed women in Pocket 1 reported being harassed. They identified "maledominated spaces" and "absence of people/vendors" as the main causes of harassment, as also mentioned in the literature. The Lower Promenade's inability to attract higher footfall throughout the day and the el- evation difference between the Upper and the Lower Promenades reduces visibility and encourages predators. Thus, $65 \%$ of women mentioned they were harassed on the Lower Promenade. Most young girls and women reported young boys engage in eve-teasing and catcalling in this pocket. A 19-year-old Hindu student pointed out: "The boys standing on the Upper Promenade frequently pass comments, whistle, and sometimes secretly take photographs of us (group of girls)!" Our mapping also showed that no woman was found using this space by herself. Women came to 


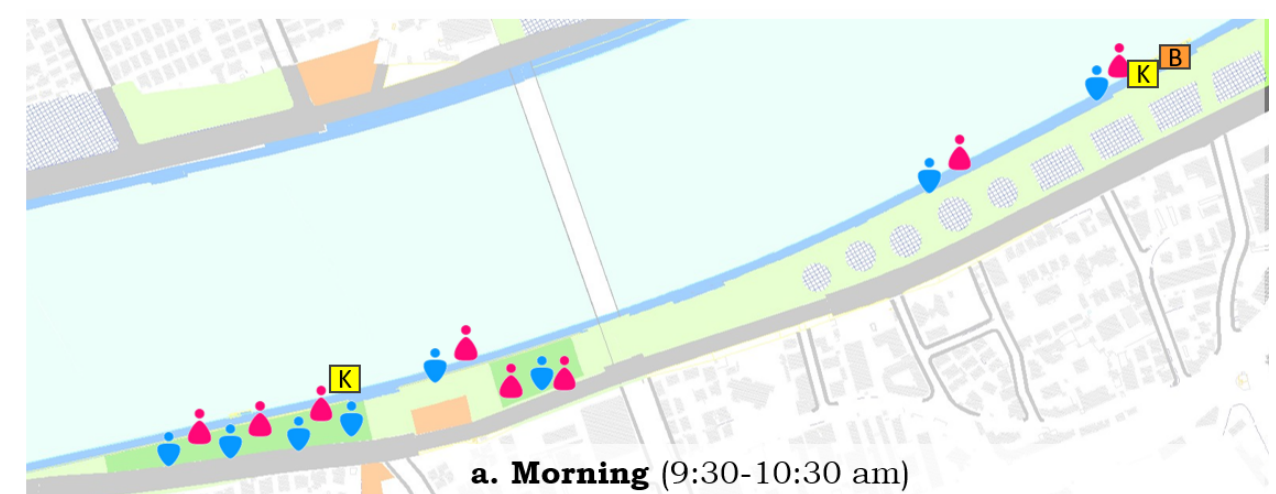

Approximate people: 80; Males- 40; Females- 40

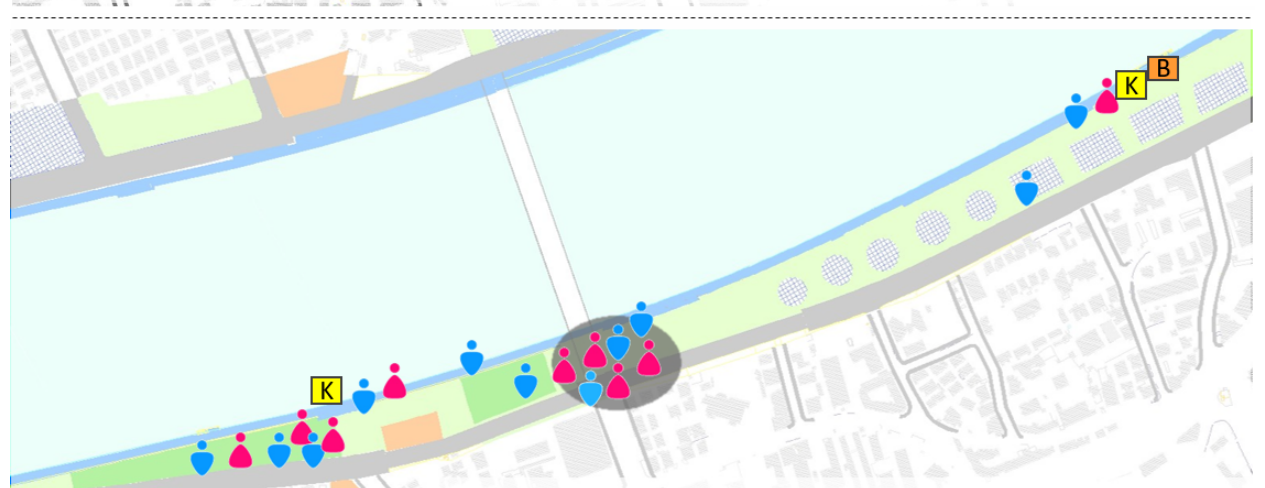

b. Afternoon (1:30-2:30 pm)

Approximate people: 100; Males- 55; Females- 45

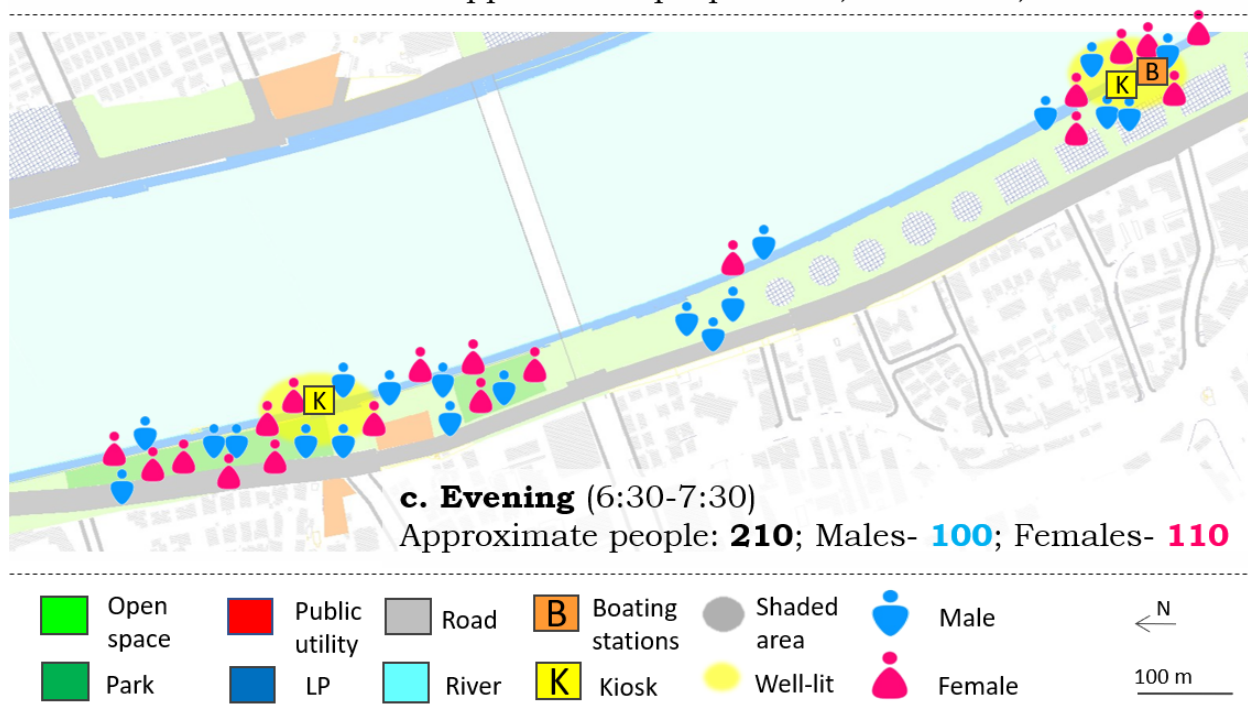

Figure 3. Gendered usage of space in Pocket 1.

this segment of the riverbank always accompanied by friends or family.

\subsection{Pocket 2: Paldi Square (between Stretch $G, H$ )}

Pocket 2, Paldi Square, is one of the largest spaces on the western side of the Riverfront. Again, another bridge named Sardar Bridge divides the Upper Promenade into two very different parts. The Events Ground located north of Sardar Bridge is closed off to the public and is only rented out for mega-events like religious sermons, large-scale weddings or receptions, or used for medium-sized city activities like the Annual Flower Festival of Ahmedabad. The sports facility to the south of the Sardar Bridge regularly hosts local sports tournaments and matches. The Lower Promenade is designed as a huge public square that easily transforms into a 'Valentine's Day' and 'New Year's Eve' destination.

Mornings in Pocket 2 are very busy when the residents from the adjoining neighborhoods are found walking, cycling, and exercising on the Lower Promenade, after which they gather around the two food kiosks on 
the Lower Promenade. The inner stretches of the Lower Promenade are poorly lit and usually deserted, making women prone to harassment. The sports facility is full of young and middle-aged men playing cricket daily starting at 5:30 am. Women in this spot are a rare sight, further intimidating any woman who wishes to play sports there (refer to Figure 4a). Most women admitted that they only use Pocket 2 when they are in a group or have male company. A 25-year-old Muslim housewife confessed: "In winters, the place is a bit dark....That scares me! I am very worried if I can't keep up with my husband while walking in the morning, as the thought of being alone is daunting!" Cultural norms dictate activities that young women can take up; and playing in an open space is not one of these. As discussed in the literature, better-lit spaces create the perception of safety and the congregation of many men creates the perception of lack of safety, which we find in this pocket.

As Pocket 2 is designed as a public square, it has a relatively more visibly accessible Lower Promenade. Despite that, the deserted space during afternoons makes women feel unsafe. The area below the Sardar Bridge is

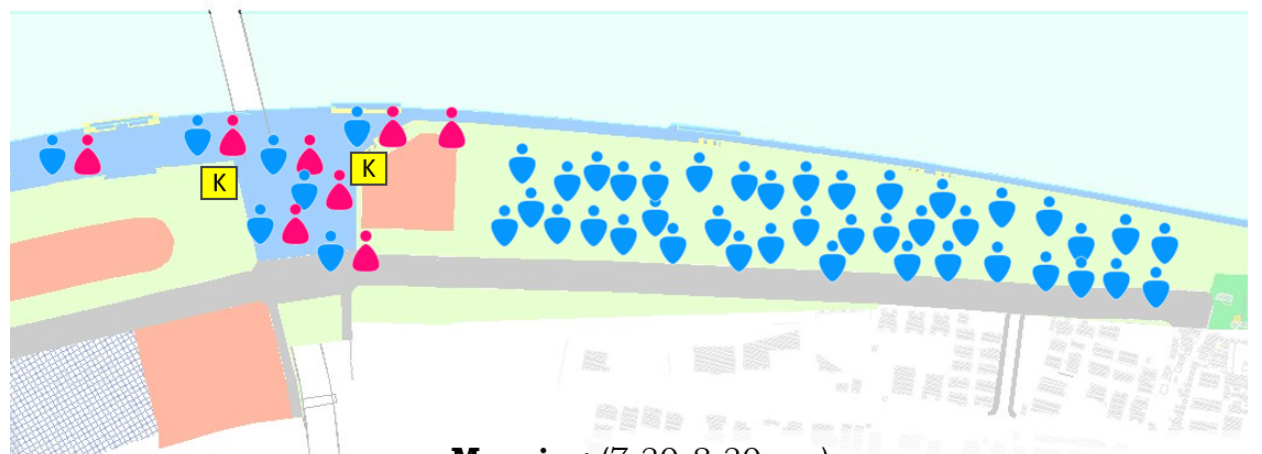

a. Morning $(7: 30-8: 30 \mathrm{am})$

Approximate people: 270; Males- 230; Females- 40

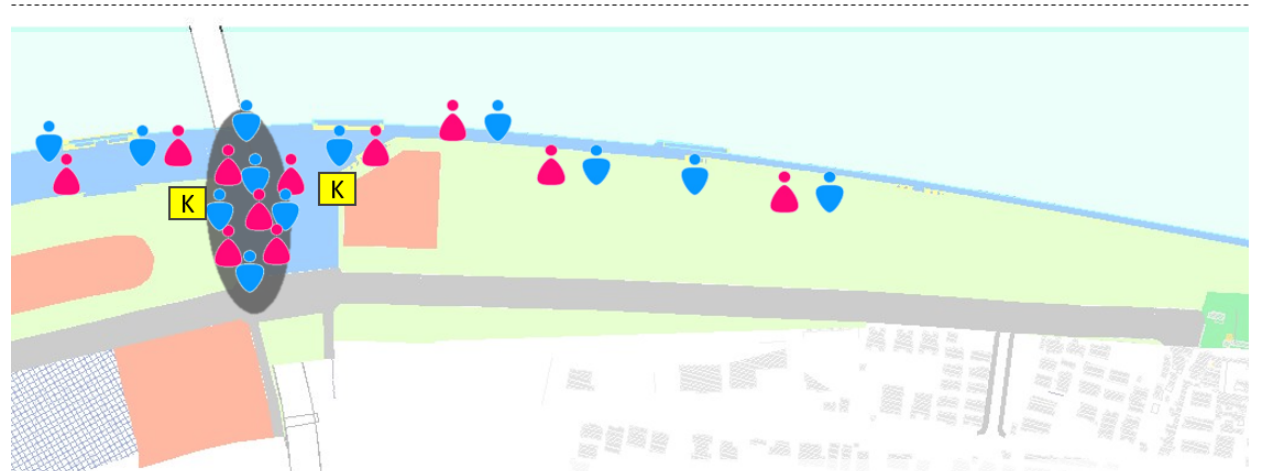

b. Afternoon (2-3 pm)

Approximate people: 125; Males- 60; Females- 65

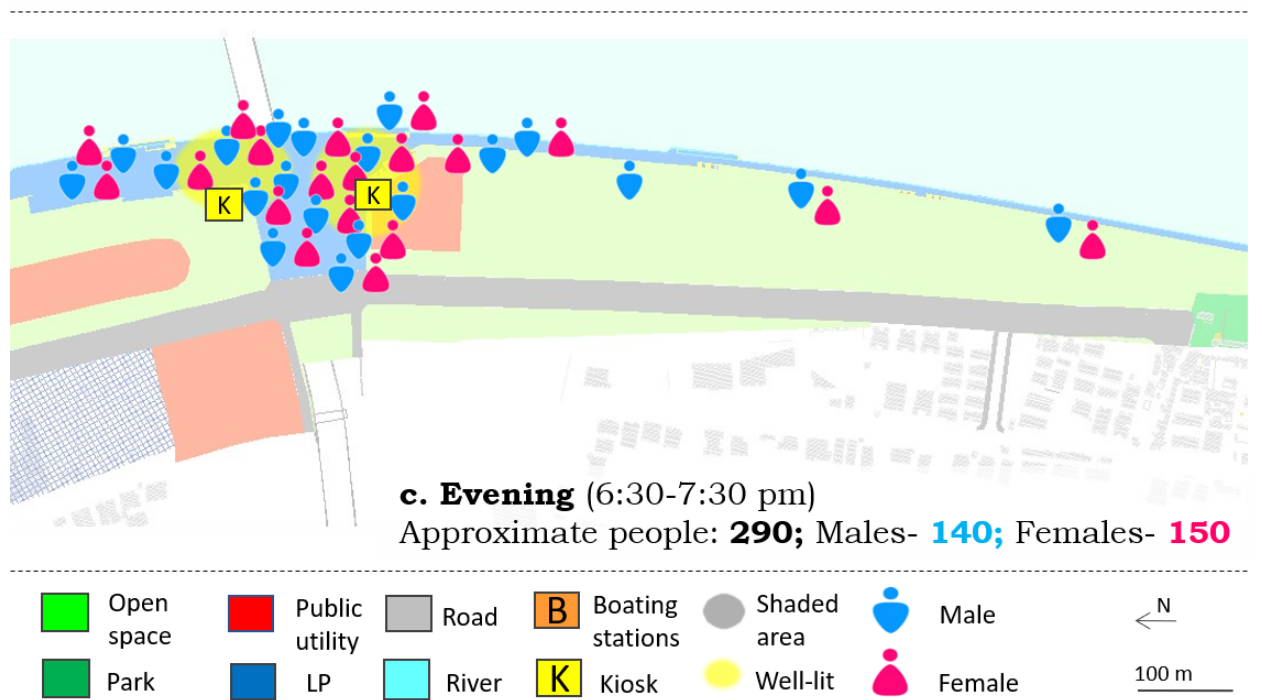

Figure 4. Gendered usage of space in Pocket 2. 
shaded and usually occupied by young students in groups or couples during this period. The Upper Promenade is sparsely populated, primarily due to lack of shaded area (refer to Figure $4 b$ ).

The evenings have large numbers of people flocking, who then sit on the stairs and Ghats. A large number of families gather around the food kiosks on the Lower Promenade and a children's play area on the Upper Promenade, both these areas being the only well-lit areas in this pocket (refer to Figure $4 \mathrm{c}$ ). All other areas in this pocket are known for thefts and security issues. This pocket is infamous for the number of suicides attempted from the bridge. These factors have resulted in strict and constant surveillance through CCTV and Police patrolling. A policeman stationed close to Pocket 2 informed: "We installed around 70 cameras in the entire stretch....The moment we see any suspicious activity; we immediately reach there! There's nothing to worry about on the Riverfront!"

Despite this, an overwhelming majority of women admitted facing harassment or robbery. Women are not seen using the space by themselves in this pocket too. A 18-year-old local resident said: "What impact does patrolling alone have!? Accidents can take place anywhere at any time! I'm in constant fear, especially in the early mornings or late evenings, as there are fewer people around." 8 out of 10 women complained that men gathered in groups near the sports facility often pass lewd comments and whistle. $60 \%$ of women reported being harassed in the inner stretch (Lower Promenade) due to the reasons mentioned above and poor lighting. But the majority of the interviewed women mentioned feeling safe in the square. A 23-year-old, upper-class student summarized her experiences of harassment:

I have been robbed twice! Cat-calling, eveteasing....These things have happened multiple times! Earlier, I used to come alone in the mornings to exercise. Then, due to such experiences, I only come with my friends! It's very irritating how such things happen repeatedly in such a large public space! These security guards are also useless. Plus, who knows if these CCTV even works! Many of my friends (girls) have had such unpleasant experiences a lot of times.

\subsection{Pocket 3: Subhash Park (Stretch C \& Parts of D)}

Located between two important bridges of the city, in the East Zone of Ahmedabad, Pocket 3 is one of the biggest Parks in Eastern Ahmedabad and is called Subhash Park. This is a gated park with a "nominal" entry fee. It is well landscaped and maintained and has features such as an Amphitheatre, a lotus pond, and a big tot-lot (kids playing area) that brings in diverse user groups.

The park has free entry from 6:00 to 8:00 am to allow nearby residents to use it for walking, jogging, and morning workouts. Despite Pocket 3 having the widest Lower Promenade on the Riverfront, residents seldom use it during the mornings (refer to Figure 5a). The youth, in groups and in pairs, are the predominant user group during late mornings. Heterosexual couples are often found behind the trees and bushes, near the Upper Promenade wall as it has the least visibility from the Park. Women reported feeling safer due to the park's 'gated' nature that "filters out nuisance-causing people." A young, upperclass female respondent pointed out: "The Riverfront is not safe, but Riverfront/Park is totally safe! Although, sitting on the Lower Promenade makes me feel quite insecure! Boys standing on the Upper Promenade keep staring (at me). They even whistle and hoot if there are fewer people around."

The footfall decreases considerably during the afternoons. Like the previous two pockets, clusters of people in Pocket 3 are also on the Lower Promenade, below the bridges. Most women have reported multiple cases of harassment during this time slot; mainly due to lack of activities and visibility (refer to Figure 5b). Again, harassment was reported despite no woman stating that she came alone to the riverfront. And again, the lack of activities increases the sense of lack of safety.

Pocket 3 has the most vibrant evenings on the Riverfront. Large clusters of different user groups like families, youth in pairs and groups, older adults, middle-aged workers, etc. can be found. Women cluster around the Tot Lot to keep an eye on their children while they play. The food kiosks and the Boating Station on the Lower Promenade are major attractions for families and youth (refer to Figure $5 \mathrm{c}$ ). This pocket is lined with different kinds of lights, with an Amphitheatre, Lotus Pond, Tot Lot, food kiosks and Boating Station which are extremely well lit. The majority of women said they feel safe in the Park but there were spots in the inner stretches of the Lower Promenade where they experienced visual/verbal harassment.

Sixty percent of respondents reported experiencing harassment here, the highest among all pockets. Over $70 \%$ of women expressed fear of being alone in Pocket 3. They confessed to always moving around in large, mixed (gender) groups or with their families to reduce the risk of harassment. Women in this pocket reported facing multiple forms of harassment like visual, verbal, and stalking. $75 \%$ of the harassed women reported the incident occurred in the Lower Promenade. A 23-year-old professional mentioned: "They (young men) catcall, they constantly stare at us (girls) and at times, even stalk us. These things have now become like a part of our routine! And I feel that such nuisances are here to stay! What can one do about it?"

\subsection{Pocket 4: Stretch near the Sunday Market (between Stretch $F, G)$}

Pocket 4 is between the two iconic bridges, Ellis Bridge and Nehru Bridge, close to the Walled City of Ahmedabad, in eastern Ahmedabad. Unlike the other pockets, there are no major amenities and it is one of the 

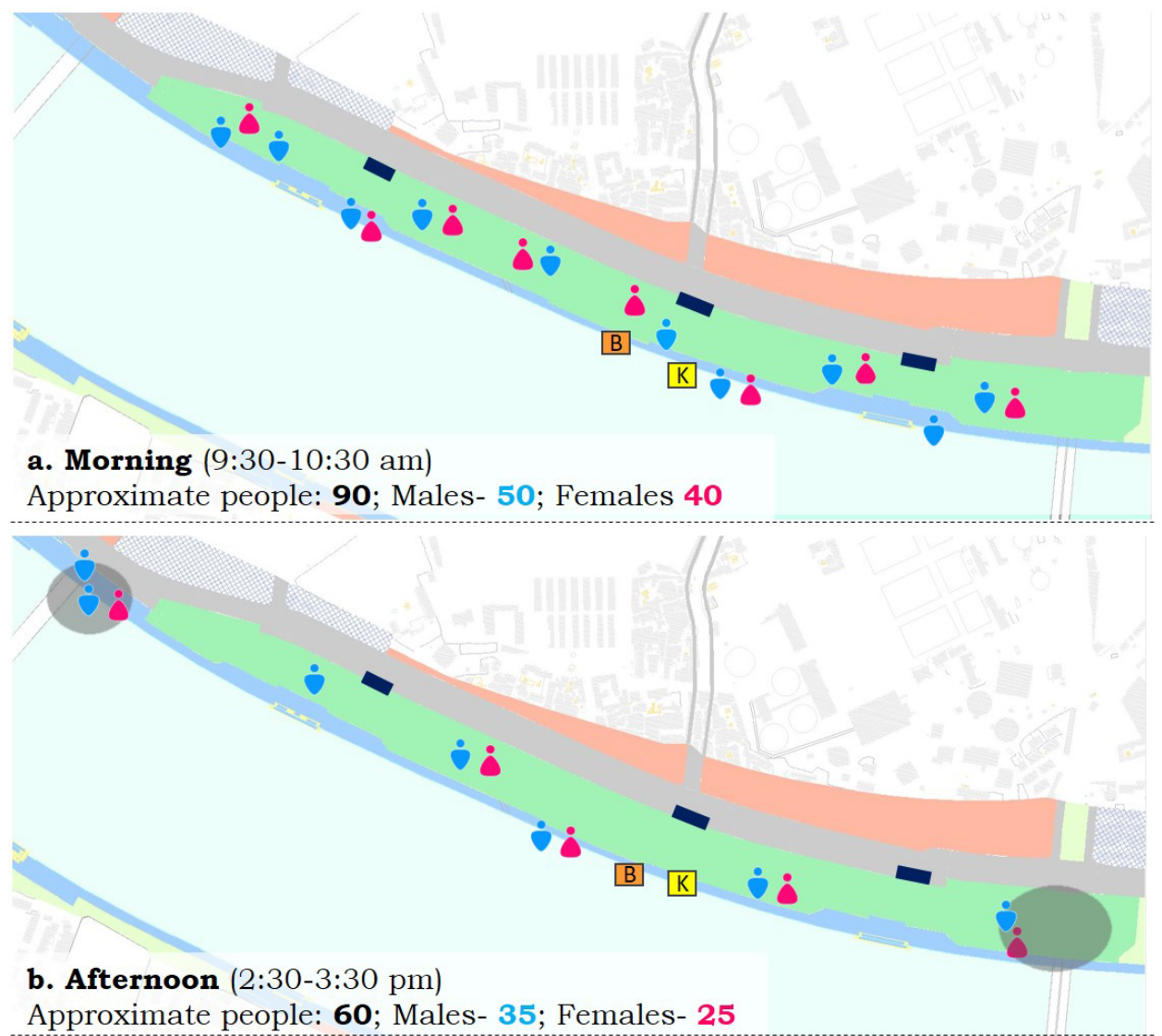

Approximate people: 60; Males- 35; Females- 25

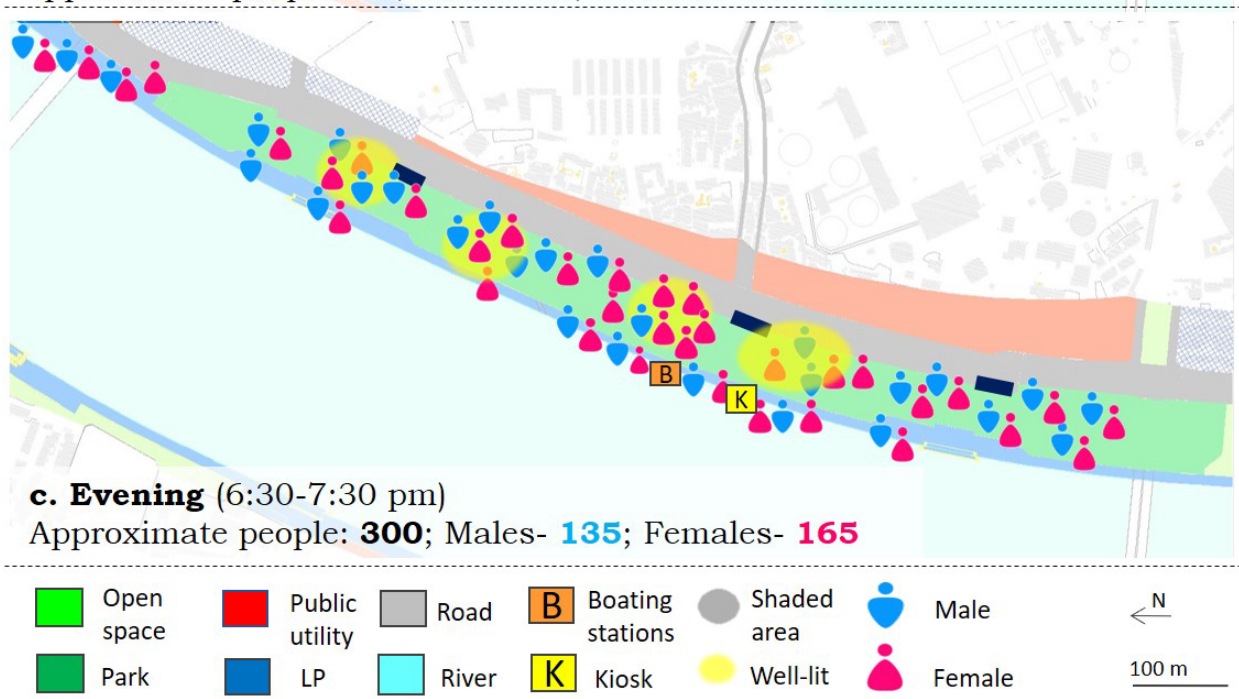

Figure 5. Gendered usage of space in Pocket 3.

most poorly maintained spots among all the four pockets. The stretch is active only on Sundays due to Ravivari (Sunday Market), which is held in the vicinity. The crowd from Ravivari (Sunday Market) often spreads on both sides of Ellis Bridge and all the way up to the central plaza in the Walled City.

Men openly defecate in the Lower Promenade of Pocket 4 during the early mornings. The Upper Promenade is often used for openly urinating and spitting. Very few women use Pocket 4 in the mornings as they find the spot "unpleasant" and "uncomfortable" to use. All women who walk or jog here prefer a male companion with them. This pocket is also poorly lit, making women feel more prone to harassment during the mornings (refer to Figure 6a). All women mentioned that the poor maintenance of walls, Ghats, promenades, and especially the polluted water in the river constantly bothered them. A 23-year-old Muslim housewife explained: "Lots of men openly defecate here in the morning! It really stinks, and if a woman witnesses any man in that state, it causes problems....People must understand and stop defecating like this! It's such a nuisance." 
The afternoons are very deserted, with almost no women even on the Upper Promenade in Pocket 4. Women respondents surveyed in other pockets refer to this pocket as one of the "most unsafe" spaces on the Riverfront, mainly for being a "male-dominated space" and "abandoned" in the afternoons (refer to Figure 6b).

More women use the space in the evening as they bring their children here to play. Again, women use the space for a 'legitimate' reason and are accompanied by others. They mention that a lack of open spaces in their neighborhoods forces them to bring their children here despite the poor quality of space. The place is darker in the evenings due to lack of lighting (refer to Figure 6c). Most women reported feeling more unsafe in the evening than at any other time of the day. The nearby residents are the predominant users of Pocket 4 and return to their houses by sundown. This leaves the place totally empty at night, making it more prone to illicit activities and harassment. A 28-year-old housewife said: "I usually feel safe when I see more families or women around! All these young men cause all the trouble!"

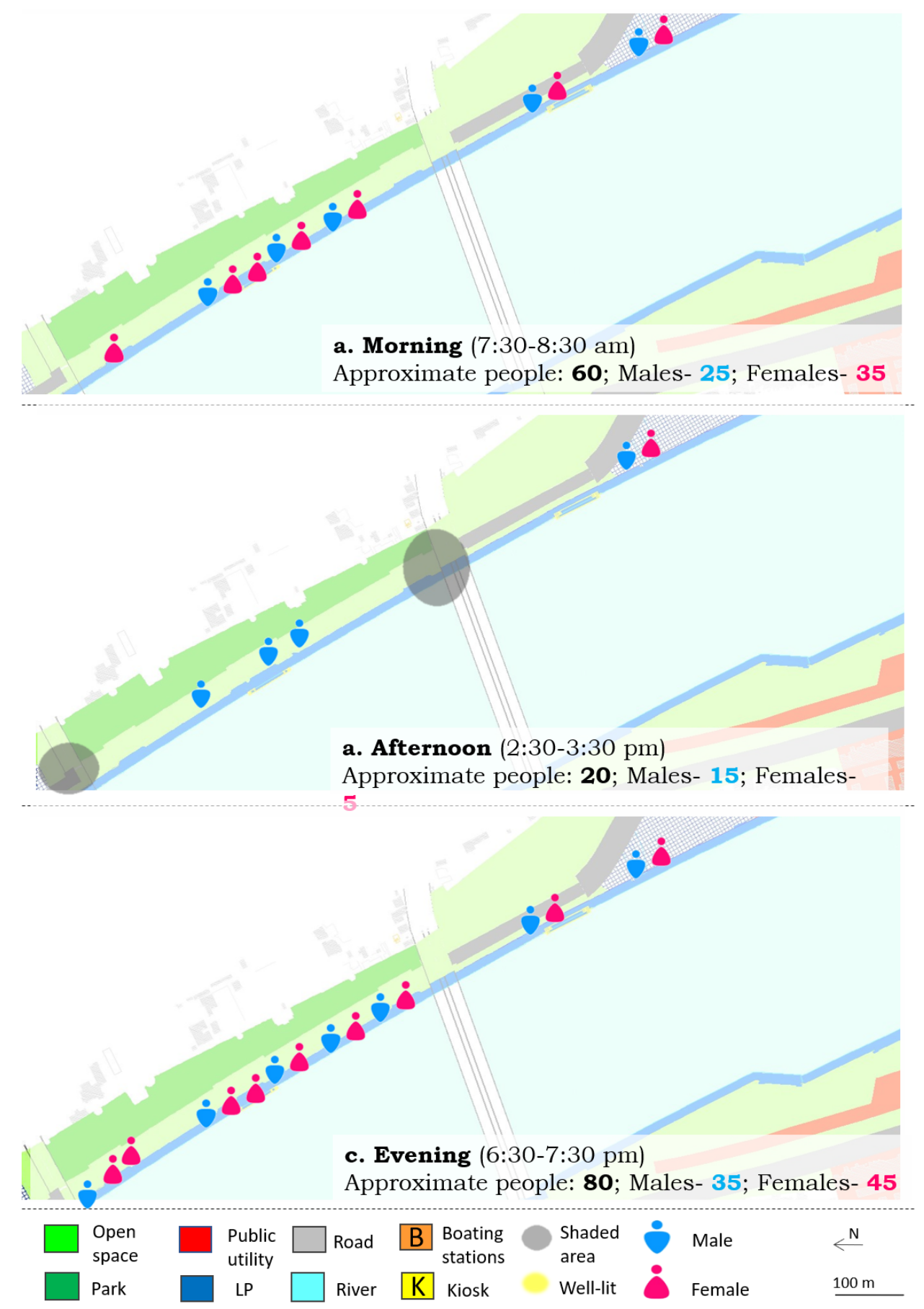

Figure 6. Gendered usage of space in Pocket 4. 
$35 \%$ of women reported facing harassment in this pocket, the lowest rate among all. The main reasons for this may be, first, very few women visit this pocket and when they do, they usually have male company. And second, this pocket has the shortest elevation difference between Upper Promenade and Lower Promenade, increasing visibility. So unlike other pockets, harassment on the Lower Promenade was rare. Instead, most women were harassed near and below the bridges, the darkest and polluted parts of the pocket. All women mentioned feeling uncomfortable when they encounter men openly defecating or urinating on the Upper Promenade. A 24-year-old practicing doctor expressed her coping mechanism for harassment: "Generally, there is no safe place for girls and women! So, I think it's better to not go out alone, especially to a deserted place, or after dark!"

\section{Conclusions and Recommendations}

Overall, of the 100 interviewed women, 52 of them reported being harassed at least 3-4 times. It is important to note that the samples were collected from the 'most active' spots/pockets of the Riverfront and that too, wherein women were always accompanied by a group of friends, male partners or family. 49 surveyed women reported verbal harassment, 46 visual harassment, and 11 stalking. During the study period, no cases of physical assault were reported in any of the pockets. As stated earlier, social and cultural barriers, requiring a stamp of virtuosity, and living in constant fear of harassment or sexually violation prevents single women from using this public space.

The main causes of harassment were identified as (a) male-dominated spaces (53\%) and (b) fewer people and vendors around (38\%). $51 \%$ of harassed women reported the incidents took place in the afternoon, followed by $37 \%$ in the evening, and $15 \%$ in the morning. It is interesting to note that most women reported feeling unsafe in the early morning and evening but were harassed the most in the afternoon. $67 \%$ of all women reported being harassed on the Lower Promenade. In almost all pockets, built environment factors that reduce visible accessibility, fail to bring and engage people, plus poor maintenance made the Lower Promenade favorable for predators. Also, perception of insecurity was enhanced by cultural factors such as male-dominated spaces because women do not loiter or sit in public spaces; women require a purpose to come out of their homes, as discussed in the literature. Land use planning and city policy of not allowing vendors in areas declared as 'no vending zones', e.g. the riverfront, has also created a situation of lack of safety for women.

Most women have accepted harassment as a part of their reality and have mechanisms to cope with it. Many women reported changing how and when they engage with the Riverfront. $90 \%$ of women believed that moving in "mixed-gender groups" or having male company reduced the risk of harassment/violence. Thus, the majority of women found the harassment as "not too harmful" and "not too bothersome". As observed in various studies of Mumbai (Phadke, 2007) and Delhi (Jagori, 2010), this normalization of everyday harassment and violence curbs women's "right to the public space" in Ahmedabad. The normalization of everyday harassment and the threat of violence, or violence, negate the possibility of achieving SDGs 5 and 11.

In summary, our study indicates that (i) women tend to avoid using the riverfront in the early morning and late evening. They are usually accompanied by their friends or family and use the space for leisure or recreation; (ii) women prefer spots that are well-lit, well-maintained, and receive more footfall or spots that are generally more active. As found in the literature above, these elements make them feel safer as they think they can be heard, seen, and get help; (iii) The societal notion of women's safety emphasizing on sexual safety to safeguard their and their families' honor prevents women from using the riverfront independently. Thus, single women are barely spotted in the large public space; (iv) $52 \%$ of women reported they were harassed, predominantly on the lower promenade during afternoons. Out of all the four pockets, Pocket 3 has the highest rate of harassment (60\%); and ( $v$ ) most women emphasized increasing informal and formal surveillance through regular activity generation, vending zones, police personnel, and CCTV cameras. As observed in the literature above, many women recommended better maintenance of all pockets and adding design elements that increase public convenience like water stations, accessible public toilets, seats/benches, and shaded spaces (trees, umbrellas, etc.).

\subsection{Recommendations}

To meet the targets of SDGs 5 and 11, increasing surveillance (that isn't unobtrusive) is essential in many parts of the riverfront, especially the LP, always. This can be done through both informal and formal surveillance. Increasing female police personnel in and around the visual and hearing isolation areas may be very effective in making women feel safe. In addition, the everyday governance of these public places needs to improve through timely waste management, improved lighting, providing enough clean toilets, and maintaining hygiene.

Offering a diverse range of activities like Khao Gali (food streets) on both sides, adding barrier-free sports facilities, a shopping street with shops which sell artisanware as well as traditional clothes, and more public parks with play areas for children, water sports, spaces for public institutions, town halls \& community centers, will generate co-benefits of increasing footfall and improving women's safety, allowing more women to freely engage with and enjoy the Riverfront. The Riverfront is used for city-level events like Kite Festivals, a shopping festival (January 2019), and the Annual Flower Festival. Allotting spaces for performing arts (music, theatre, dance, etc.), 
cultural activities, and Biological Parks can ensure regular activity generation. The Biological Park, community gardens, and other green spaces can be used for education and environment drives.

Considering the survey results, it is essential to introduce a gender dimension in the planning and design of this space. Improving the visual accessibility of the LP by repurposing spaces around the stairs, Ghats, etc. is vital. The city has proposed large-scale mixed-use developments along the UP. Thus, creating a larger public realm through careful urban design and building guidelines that maximize the visual and physical connection to the Riverfront is essential for women's safety. Lastly, introducing public and paratransit facilities like feeder buses and E-rickshaws will make the Riverfront accessible to people and reduce air pollution. Hence, an integrated transportation plan that links the feeder buses to the existing AMTS and BRT network and includes other clean mobility initiatives, like E-rickshaws and MyByk, is highly recommended.

\section{Acknowledgments}

We would like to thank Sabarmati River Front Development Corporation Ltd (SRFDCL), for providing base maps of the Sabarmati Riverfront Development. We thank Saumya Lathia's parents, Sunita Lathia and Mukesh Lathia, for accompanying her on all site visits. We are deeply grateful to all the girls and women on the Riverfront who provided invaluable inputs and shared their experiences of harassment.

\section{Conflict of Interests}

The authors declare no conflict of interests.

\section{References}

ActionAid International. (2013). Women and the City II: Combating violence against women and girls in urban public spaces: The role of public services. Johannesburg: ActionAid International.

Beall, J. (1996). Participation in the city: where do women fit in? Gender and Development, 4(1), 9-16.

Desai, R. (2014). Municipal politics, court sympathy and housing rights: A post-mortem of displacement and resettlement under the Sabarmati Riverfront project (Working Paper, No. 23). Ahmedabad: Centre for Urban Equity, CEPT University.

Desai, R., Parmar, V., Mahadevia, D. (2017). Resettlement, mobility and women's safety in cities. I/C Quarterly, 43, 65-76.

Dhar, S. (2013). Mixed city spaces are safe city spaces. New Delhi: Women's Feature Service.

Jacobs, J. (1992). The death and life of great American cities. New York: Vintage Books.

Jagori. (2007). Is this our city? Mapping safety for women in Delhi. Delhi: Jagori.
Jagori. (2010). Understanding women safety: Towards a gender inclusive city. Delhi: Jagori.

Kabeer, N. (1994). Reversed realities: Gender hierarchies in development thought. London: Verso.

Lips, H. (2015). Gender: The basics. London: Routledge.

Mahadevia, D. (2014). Institutionalizing spaces for negotiations for the urban poor. In O. P. Mathur (Ed.), Inclusive urban planning: State of the urban poor report, 2013 (pp. 148-166). New Delhi: Ministry of Housing \& Urban Poverty Alleviation, Government of India, and Oxford University Press.

Mahadevia, D., Desai, R., \& Vyas, S. (2014). City profile: Ahmedabad (Working Paper, No. 26). Ahmedabad: Centre for Urban Equity, CEPT University.

Moser, C. O. N. (1993). Gender planning and development: Theory, practice and training. London: Routledge.

Parichiti. (2012). Report on the safety audits conducted in Dhakuria, Bagha Jatin and Ballygunge stations, Kolkata. Kolkata: Parichiti.

Phadke, S. (2005). You can be lonely in a crowd: The production of safety in Mumbai. Indian Journal of Gender Studies, 12(1), 41-62.

Phadke, S. (2007). Dangerous liaisons-Women and men: Risk and reputation in Mumbai. Economic and Political Weekly, April, 1510-1518.

Phadke, S., Ranade, S., \& Khan, S. (2009). Why Loiter? Radical possibilities for gendered dissent. In M. Butcher \& S. Velayutham (Eds.) Dissent and cultural resistance in Asia's cities (pp. 185-203). London and New York, NY: Routledge.

SAKHI. (2011). Are cities in Kerala safe for women? Research findings of the study conducted in Thiruvananthapuram and Kozhikode cities, Kerala 2009-11. Thiruvananthapuram: SAKHI.

Sur, P. (2014). Safety in the urban outdoors: Women negotiating fear of crime in the city of Kolkata. Journal of International Women's Studies, 15(4), 212-226.

UN Human Rights. (1993). Declaration on the elimination of violence against women. Retrieved from http://www.ohchr.org/EN/Professionallnterest/ Pages/ViolenceAgainstWomen.aspx

UNHABITAT, Department of Women and Child Development, Government of NCT of Delhi, Jagori, \& UN Women. (2010). A draft strategic framework for women's safety in Delhi, 2010. New Delhi: Jagori.

UNHABITAT, Women in Cities International, SIDA, Huairou Commission, \& CISCSA. (2008). The global assessment on women's safety. Nairobi: UNHABITAT. Retrieved from http://www.preventionweb.net/ files/13380_7380832AssesmentFinal1.pdf

Vishwanath, K., \& Mehrotra, S. T. (2007). 'hall we go out?' Women's safety in public spaces in Delhi. Economic and Political Weekly, April, 1542-1548.

Vishwanath, K., \& Mehrotra, S. T. (2008). Safe in the city? Retrieved from http://www.india-seminar. com/2008/583/583_kalpana_and_surabhi.htm

Women in Cities International. (2010a). Together for 
women safety, creating safer communities for marginalized women and everyone. Montreal: Women in Cities International.

Women in Cities International. (2010b). Learning from women to create gender inclusive cities: Baseline findings from the gender inclusive cities programme. Montreal: Women in Cities International.

\section{About the Authors}

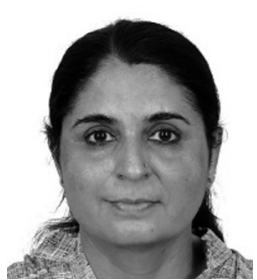

Darshini Mahadevia, Visiting Professor at the School of Arts and Sciences, Social Science Division, has over 25 years of experience in teaching and research in urban studies, human and gender development, poverty and inequality, and climate change. Darshini Mahadevia has a PhD from the Centre for Studies in Regional Development, Jawaharlal Nehru University, New Delhi. She is a member of the Editorial Board of several journals. She has more than 100 publications, which include books, chapters in books, and journal articles. She has managed more than 40 research projects.

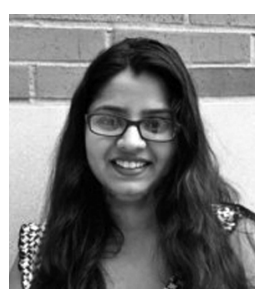

Saumya Lathia is a master's student of Planning at USCSol Price School for Public Policy. She received her Bachelor's in Planning from CEPT University at Ahmedabad, India, in 2016. Saumya served as a Research Assistant at Sol Price Centre for Social Innovation and CEPT's Centre for Urban Equity. Her research interests include urban and regional inequities, informal economy and housing, urban sustainability, and social justice. Saumya received the Best Gender Thesis Award for her undergrad thesis on 'Gender and Public Spaces: A Case Study of Sabarmati Riverfront' in 2017. 